\title{
Histological characterics of improving meat chopped semis
}

\section{Olha Masliichuk, Maria Paska}

Lviv National University of Veterinary Medicine and Biotechnology named after S.Z. Gzhytskyi, Lviv, Ukraine

Keywords:

Histology

lupine

flour

Elecampane

Meat

Patties

\section{Article history:}

Received 06.09.2016

Received in revised

form 13.11.2016

Accepted 30.12.2016

\section{Corresponding}

author:

Maria Paska

E-mail:

maria_pas@ukr.net

DOI: $10.24263 / 2310$

1008-2016-4-2-6

\section{Abstract}

Introduction. Holding histological characteristics of meat split semifinished components can detect, differentiate the properties of various tissue and cell structures, and to control production.

Materials and methods. Minced beef as the objects of research were improved with the replacement of $5 \%, 10 \%$, $15 \%$ of meat part with lupine flour and adding $0.5 \%$ of Elecampane root powder as aromatic raw. For microscopic examination it was used materials of developed ground meat, they were stamped and fixed in $10 \%$ neutral formalin solution. We produced cuts on Sannomiya microtome with thickness of $0.5-1 \mathrm{~cm}$, they were stained with hematoxylin and eosin, PAS reaction. Light microscopy and microphotography of histopreparations were performed with a microscope Leica DM 2500 and camera Leica DFC 450C Software Leica aplitation suite 4.4.

Results and discussion. In the of micro-samples studies of mince examples we found muscle polygonal and round fibers, cytoplasm was painted in a reddish-pink colour, and their dark blue nuclei were good noted under sarcolemma. This indicates that they used for stuffing fresh chilled meat, as among muscle fibers it was looked through pockets of fatty tissue that histologically characterized by a mesh structure. In locations slices of bacon it was showed vacuoles of various shapes and sizes, which gave the cut mesh look. Groups collected round light purple cytoplasm and nuclei of dark purple cells located in the center of polygonal shapes represent lupine flour; crumbly brown fibers show bread mass; wavy violet fibers show onion, dark brown single points marked Elecampane.

Conclusions. Histological studies showed for the PAS reaction developed content in meat semis, meat and plant parts. For hematoxylin and eosin it was determined the composition of ground meat.

\footnotetext{
$1008-2016-4-2-6$
} 


\section{Introduction}

Urgency direction is determined by the need to find new sources of complete protein and the introduction of new products with high nutritional value. Among a large number of herbal raw materials containing protein, lupine special place belongs to [1]. Production of meat chopped semis, combining compounding of raw meat and vegetable proteins, which contain valuable proteins is of particular relevance. [3] To control prescription of bookmarks meat chopped semis accordance with the regulations is important to identify the raw materials based on histological (microstructure) combined characteristics of ground meat.

Histological method is a direct method of determining the composition of raw materials and products. Microstructural studies can detect components that differentiate the properties of various tissue and cell structures [5].

Lupin was characterized by the World Congress of the United States as an important reserve of high quality proteins [3,4]. Apart from protein, lupine grain contains $25-40 \%$ nitrogen free extract, $9 \%$ more fat, $3-4 \%$ ash. Average protein content in lupine flour is $38.6 \%$ of dry matter (DM), which is 3 times higher than the Figure for wheat flour of the first grade and by $2.2 \%$ to DM for soy flour. About $90 \%$ of the total proteins content of lupine seeds presented digestible fractions - albumin and globulins, while in soybean flour - only $67 \%$. [1,2].

Elecampane root contains up to $44 \%$ of inulin. Also it was proved that Elecampane helps to restore metabolic processes, tidal forces, vitality, to return youth and health $[1,2]$.

Control of meat and meat products is the most topical issues of today. This is due to the global changes that have taken place in recent years in all areas of meat and meat processing industry [6]. Functional chopped meat products harmoniously combine high taste, nutritional value with good functional properties and provide a positive impact on human health. However, they are for wide audience of consumers and can be used regularly as a part of a normal diet with no specific recommendations.

\section{Literature review}

Method of microstructure analysis of meat raw materials, semi-finished and finished products from raw meat is used in European countries. [7] However, in most countries, this method has no legal basis. [8] There is enough powerful regulatory framework running-by specialists of the All-Russian Research Institute of Meat Industry named after V.M. Gorbatov (laboratory of microstructure research of meat) [9-12].

They use use different ways of preparing meat products with a high content of calcium for twenty years in Japan. When making burgers, schnitzels, sausages in minced meat theu add crushed animal bones. In the USA they conducted extensive researches on the production of food protein and mineral supplements on bone and bone residue. In the UK they use food processing of bones by way of Johnson - Faudler to obtain edible fat, protein and soluble food phosphate. Employees in ARRIMI (Moscow) also analyzed the possibility of using enzyme immunoassay which has high sensitivity and specificity [4]. This method is the most convenient to determine the type of meat, qualitative and quantitative composition of plant proteins, such as soy.

Meat products at different stages of processing and in finished form, retain their morphological features. Therefore, by using microstructural analysis of raw materials, intermediate or finished product can detect the presence of certain types of tissues, organs, spices and low-grade supplements, unexpected recipe reused raw materials [3, 13]. 
However, microstructural method makes it possible to conduct a quantitative analysis of individual components of the product [14]. Microstructural analysis makes it possible not only to detect fraud, but also to monitor compliance with approved meat composition formula [15,16]. So now in Ukraine they have particular interest is the use of microstructural analysis for quality control and safety of the finished products from raw meat as domestic and foreign production.

\section{Materials and methods}

For microscopic examination it was used materials of developed ground meat, they were stamped and fixed in $10 \%$ neutral formalin solution. After this fixed material was dehydrated in solutions of spirit, with ascending concentrations $\left(70,80,90,96{ }^{\circ} \mathrm{C}\right)$, it was condensed in two portions of chloroform and embedded in paraffin. We produced cuts on Sannomiya microtome with thickness of $0.5-1 \mathrm{~cm}$, they were stained with hematoxylin and eosin, PAS reaction. Light microscopy and microphotography of histopreparations were performed with a microscope Leica DM 2500 and camera Leica DFC 450C Software Leica aplitation suite 4.4. Minced beef as the objects of research were improved with the replacement of $5 \%, 10 \%, 15 \%$ of meat part with lupine flour and adding $0.5 \%$ of Elecampane root powder as aromatic raw. Lupine flour is used Class "Food", which was grown at the Institute of Agriculture of the National Academy of Agricultural Sciences. Lupine flour is a uniform fine powder of light yellow colour, neutral taste and odor. Elecampane is dried and powdered root. Smell is strong aroma, taste bitter, spicy.

It was selected 4 experimental models of ground meat (Table 1).

1 - «Control». Ingredients: beef (meat cutlet), raw oil, bread, onion, water, black pepper, salt.

$2-« 5 \% »$. Ingredients: beef (meat cutlet), raw fat, lupine flour, bread, onion, water, black pepper, root of Elecampane, salt.

$3-« 10 \% »$. Ingredients: beef (meat cutlet), raw fat, lupine flour, bread, onion, water, black pepper, root of Elecampane, salt.

$4-« 15 \% »$. Ingredients: beef (meat cutlet), raw fat, lupine flour, bread, onion, water, black pepper, root of Elecampane, salt.

Meat recipe of split semifinished products

Table 1

\begin{tabular}{|c|c|c|c|c|}
\hline \multirow[t]{3}{*}{ Raw materials } & \multicolumn{4}{|c|}{$\begin{array}{c}\text { Consumption of raw material per } 100 \mathrm{~kg} \text { of finished } \\
\text { production, } \mathrm{kg}\end{array}$} \\
\hline & \multicolumn{4}{|c|}{ Net } \\
\hline & Control & Sample 1 & Sample 2 & Sample 3 \\
\hline Beef (meat cutlet) & 54,0 & 51,3 & 48,6 & 45,9 \\
\hline lupine flour & - & 2,7 & 5,4 & 8,1 \\
\hline Fat Raw & 5,0 & 5,0 & 5,0 & 5,0 \\
\hline Wheat bread & 13,0 & 13,0 & 13,0 & 13,0 \\
\hline Rusk bread & 2,0 & 2,0 & 2,0 & 2,0 \\
\hline Onions & 3,0 & 3,0 & 3,0 & 3,0 \\
\hline Freshly ground black pepper & 0,1 & 0,05 & 0,05 & 0,05 \\
\hline Powdered Elecampane & - & 0,05 & 0,05 & 0,05 \\
\hline
\end{tabular}




\section{Results and discussion}

In the of micro-samples studies of mince examples we found muscle polygonal and round fibers, cytoplasm was painted in a reddish-pink colour, and their dark blue nuclei were good noted under sarcolemma. This indicates that they used for stuffing fresh chilled meat, as among muscle fibers it was looked through pockets of fatty tissue that histologically characterized by a mesh structure. In locations slices of bacon it was showed vacuoles of various shapes and sizes, which gave the cut mesh look. Groups collected round light purple cytoplasm and nuclei of dark purple cells located in the center of polygonal shapes represent lupine flour; crumbly brown fibers show bread mass ; wavy violet fibers show onion, dark brown single points marked Elecampane.

Figure s $1-8$ show histological sections of samples of ground meat painted:

A - hematoxylin and eosin.

B - PAS reaction (which paints the cytoplasm of plant origin in bright red-pink colour).

Figure s 9-11 show the histological sections of lupine flour, powder of Elecampane root and onions.

In sections of the control sample (Figure 1), with hematoxylin and had been stirred.eosin with eyepiece 10 and lens 10 muscle fibers have polygonal shape and have a clear path (1). Also it is noted large mesh cells and oval cells - adipose tissue (2). Fibrous loose fibers represent onions (3) because they were grinded. Single loose parts depict bread (4). Structure of minced was uniformly homogeneous, it was noted loosening fibers as stuffing

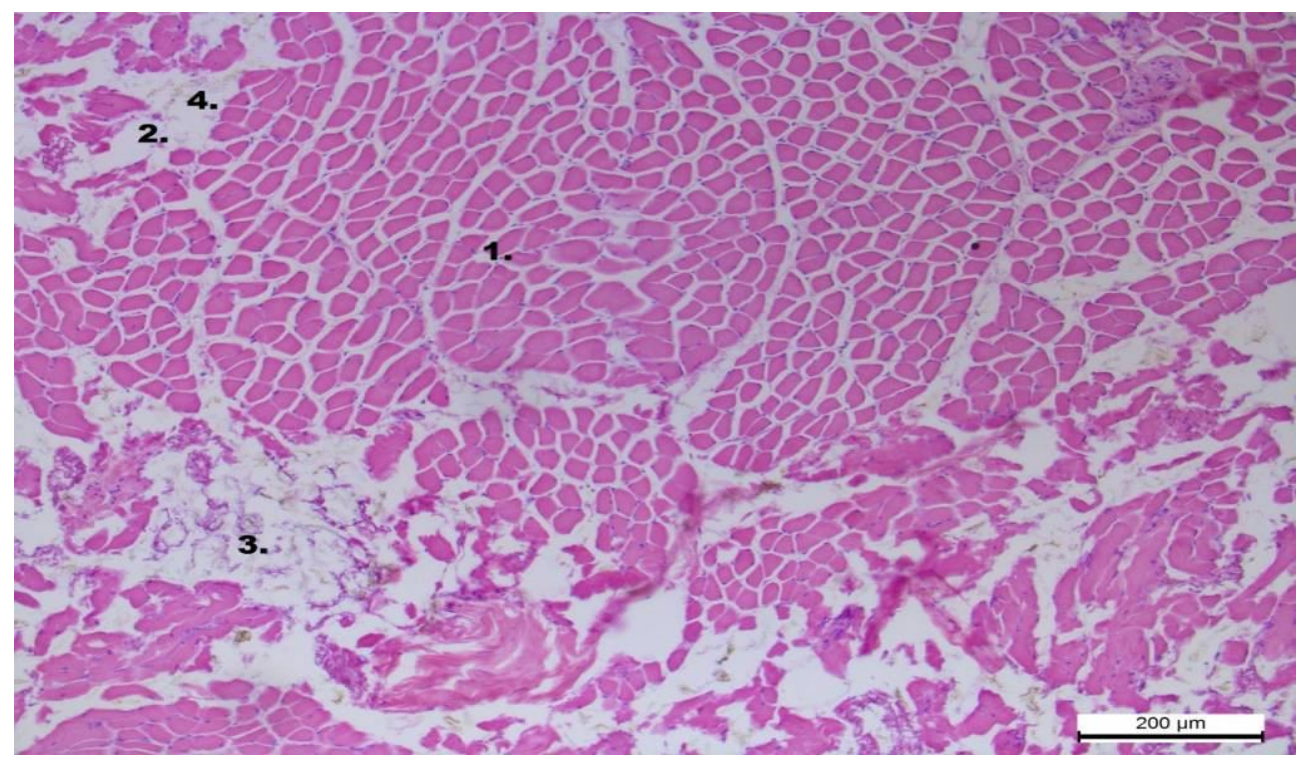

Figure 1. Sample 1 «Control», A - hematoxylin and eosin. Eyepiece 10; Lens 10. (1 - muscle fibers; 2 - fat tissue; 3 - onion; 4 - bread) 
In response to PAS reaction on the control sample cut (Figure 2) with Eyepiece 10 and lens 20 it was clearly defined plant (1) and meat (2) share. In compliance ratios which set of components and stuffing may be noted that a large proportion is a significant part of meat stuffing.

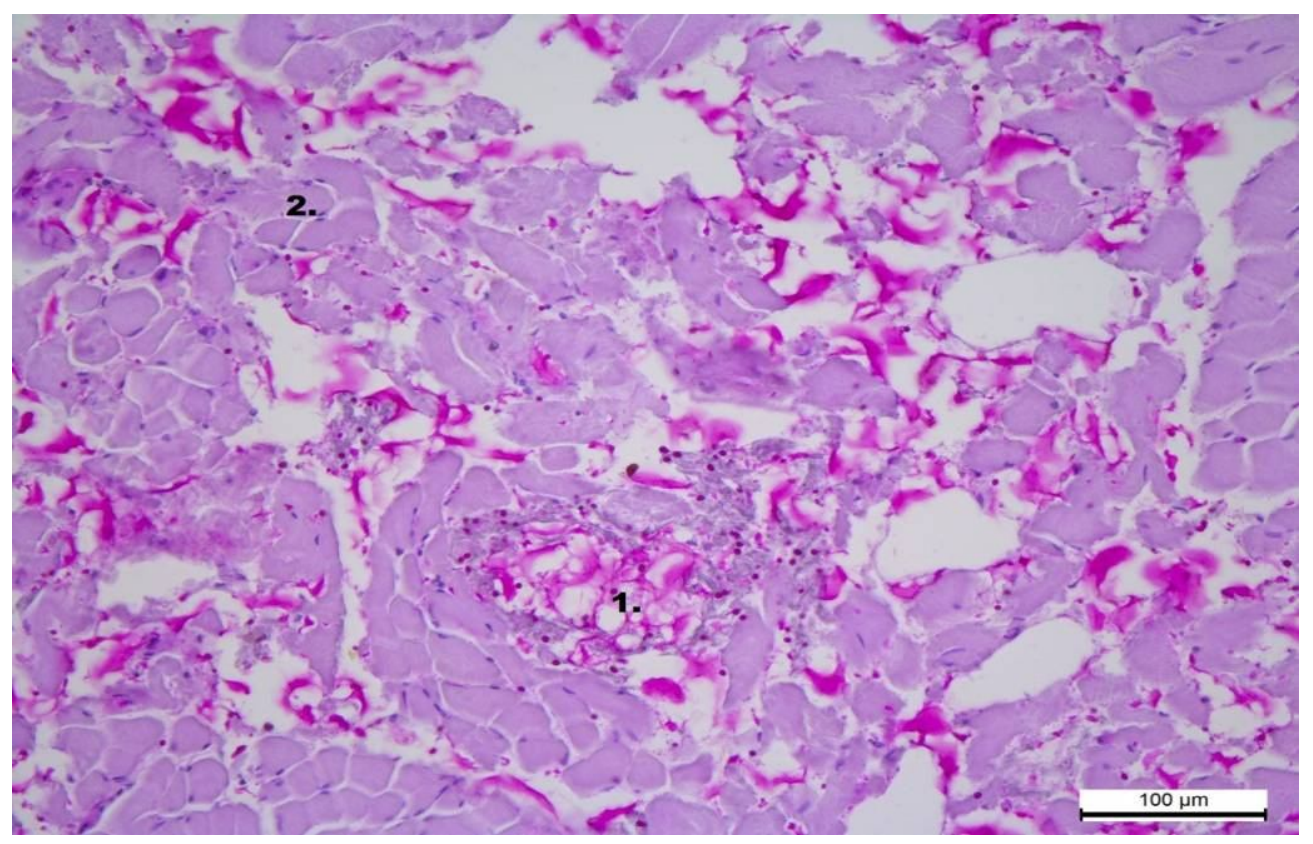

Figure 2. Sample 1 «Control», B - PAS reaction. Eyepiece 10; Lens 20. (1 - part vegetable; 2 - meat part)

In Figure 3 it is represented slice of minced with 5\% content of lupine flour and $0.5 \%$ of Elecampane root. For hematoxylin and eosin with eyepiece 10 and lens 10, it was noted the presence of muscle fibers of polygonal shape (1) with clear contours, large mesh and oval cells - adipose tissue (2), fibrous form loose fibers - onion (3) loose single fiber bread (4), vacuoles with spherical polygonal nuclei in the center of cells - lupine flour (5) and single fiber precise form - Elecampane (6). Structure of minced is uniformly homogeneous.

Figure 4 at PAS reaction with eyepiece 10 and lens 20 it was clearly defined plant (1) and meat part (2). The content of plant components increased by $5 \%$ according to recipes developed, but the content of meat particles was close to the control and remains significantly high.

In Figure 5 it was presented slice of minced with $10 \%$ content of lupine flour and $0.5 \%$ of Elecampane root. For hematoxylin and eosin with eyepiece 10 and lens 10, it was noted the presence of muscle fibers of polygonal shape (1) with clear contours, large mesh and oval cells - adipose tissue (2), fibers of loose form - onions (3) loose single fibers - bread (4), vacuoles of spherical polygonal nuclei in the center of a large cluster of cells - lupine flour (5) and single fiber of precise form - Elecampane (6). In the structure of minced small bundles are observed but are not observed uniform mixing of components in the stuffing, as lupine flour absorbs moisture. 


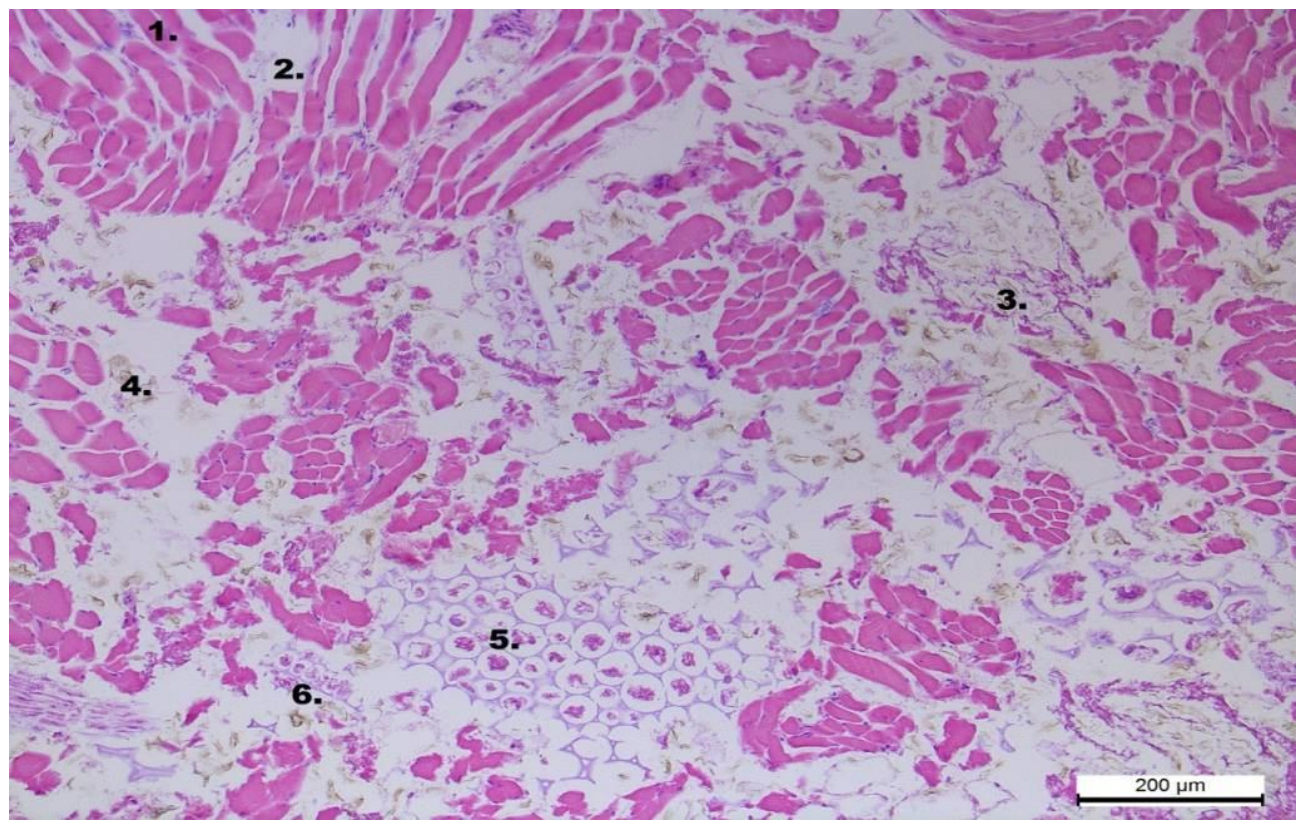

Figure 3. Sample $2 \ll 5 \% », A$ - hematoxylin and eosin. Eyepiece 10; lens 10. ( 1 - muscle fibers; 2 - fat tissue; 3 - onion; 4 - bread;

5 - lupine flour; 6 - Elecampane)

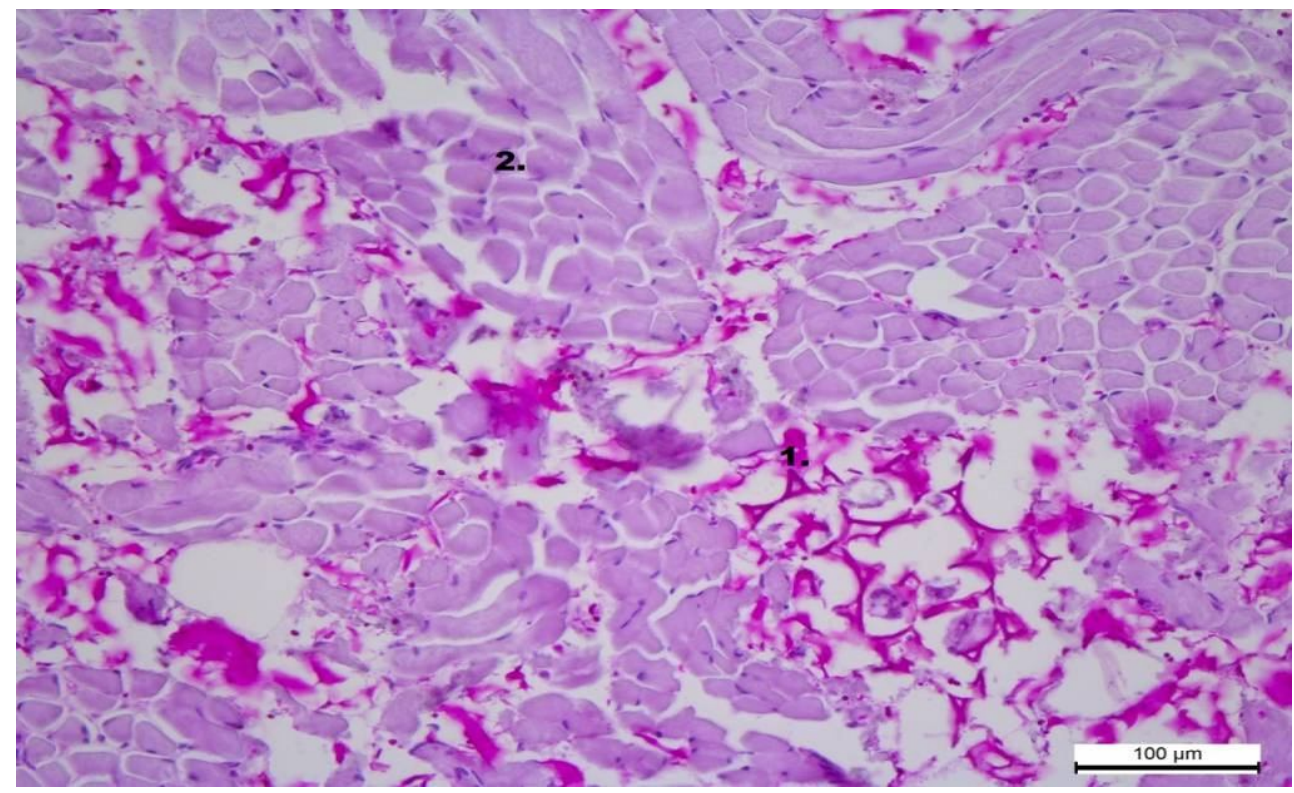

Figure 4. Sample $2 \ll 5 \% »$, B - PAS reaction. Eyepiece 10; Lens 20. (1 - part vegetable; 2 - meat part) 


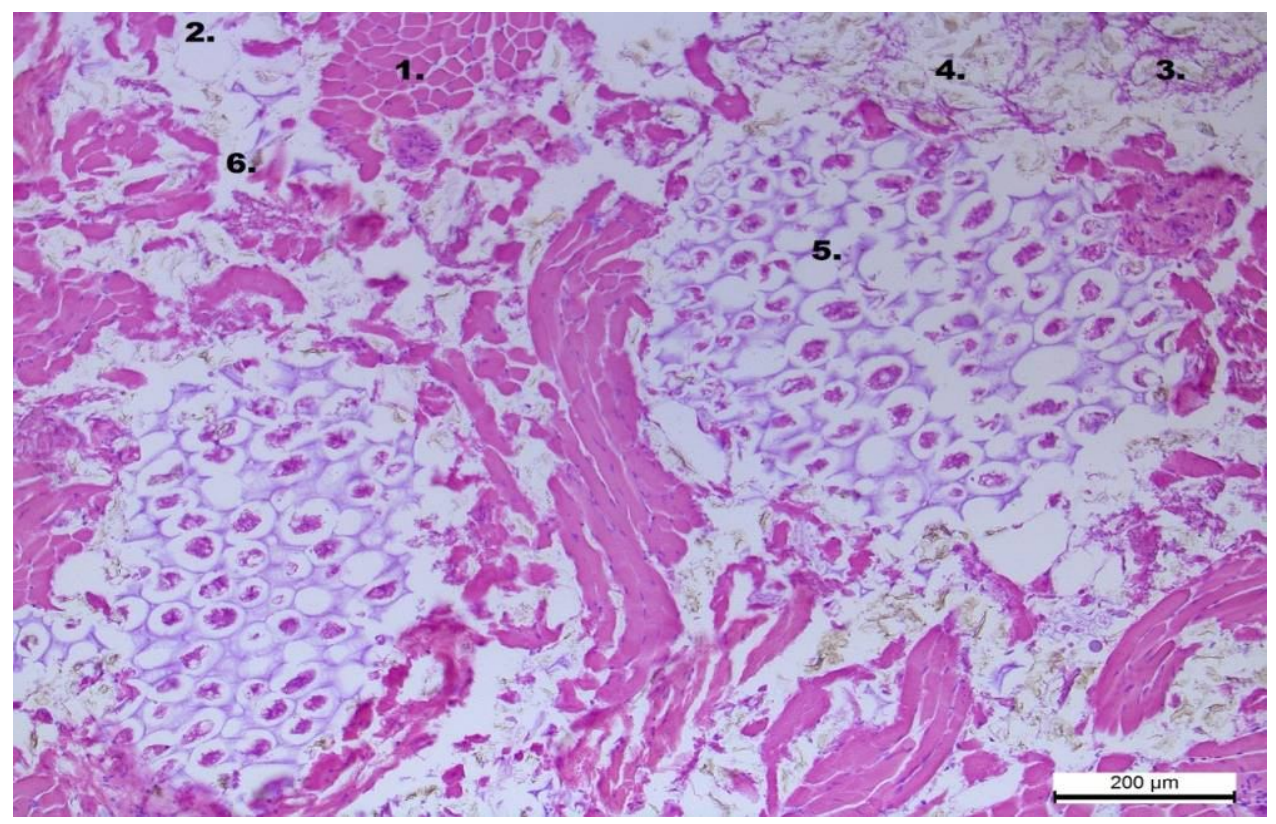

Figure 5. Sample 3 «10\%», A - hematoxylin and eosin. Eyepiece 10, Lens 10. ( 1 - muscle fibers; 2 - fat tissue; 3 - onion; 4 - read; 5 - lupine flour; 6 - Elecampane)

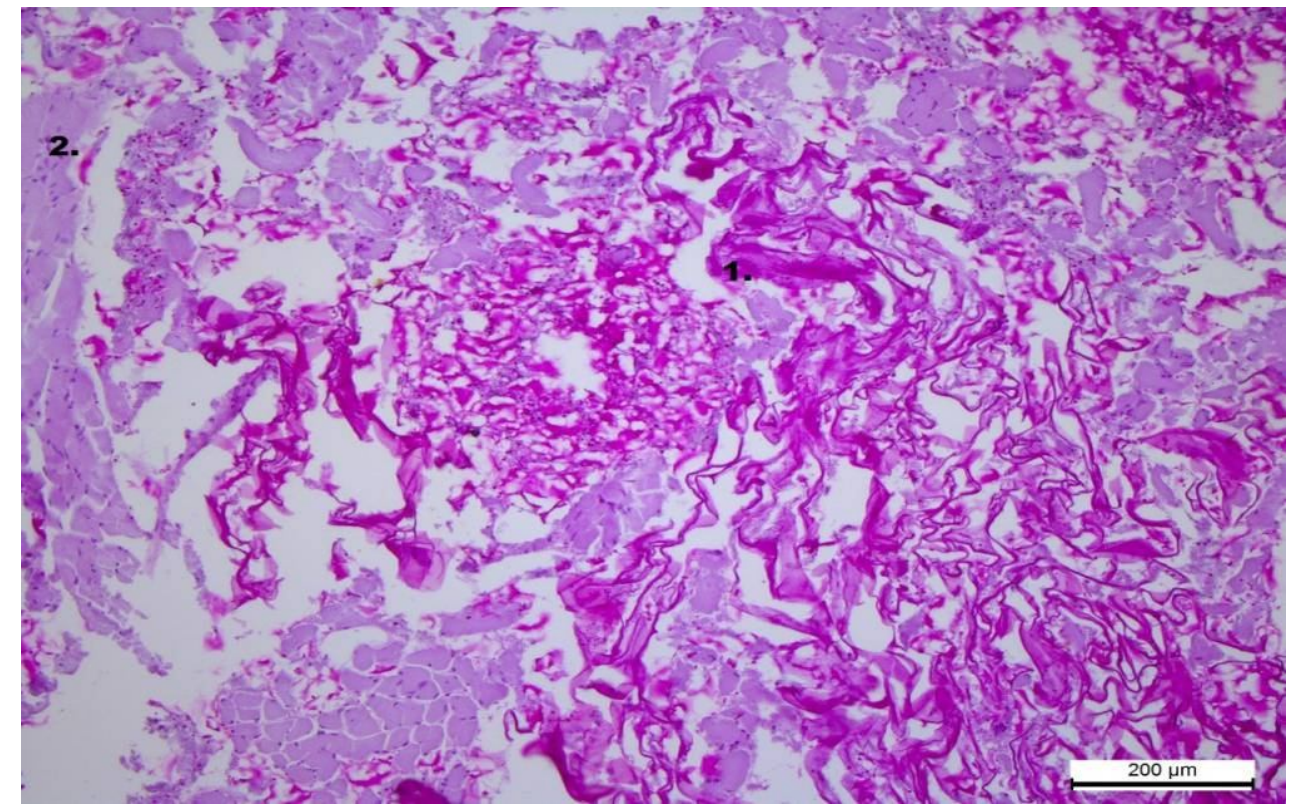

Figure 6. Sample 3 «10\%», B - PAS reaction. Eyepiece 10. Lens 10. (1 - vegetable part, 2 - meat part) 
In Figure 6 at PAS reaction with eyepiece 10, lens 10 it was identified plant part (1) and meat part (2). Vegetable share increased by $10 \%$ under developed recipes without compromising taste and organoleptic properties.

In Figure 7 it is represented slice of minced with 15\% lupine flour in content and $0.5 \%$ of Elecampane root. For hematoxylin and eosin with eyepiece 10 and lens 10, it was noted the presence of muscle fibers of polygonal shape (1) with clear contours, large mesh and oval cells - adipose tissue (2), fibers of loose form - onions (3) loose single fibers - bread (4), vacuoles of spherical polygonal nuclei in the center of a large cluster of cells - lupine flour (5) and single fiber of precise form - Elecampane (6). Structure of stuffing is broken, heterogeneous, crumbly, there is no uneven placement of muscle and plant parts.

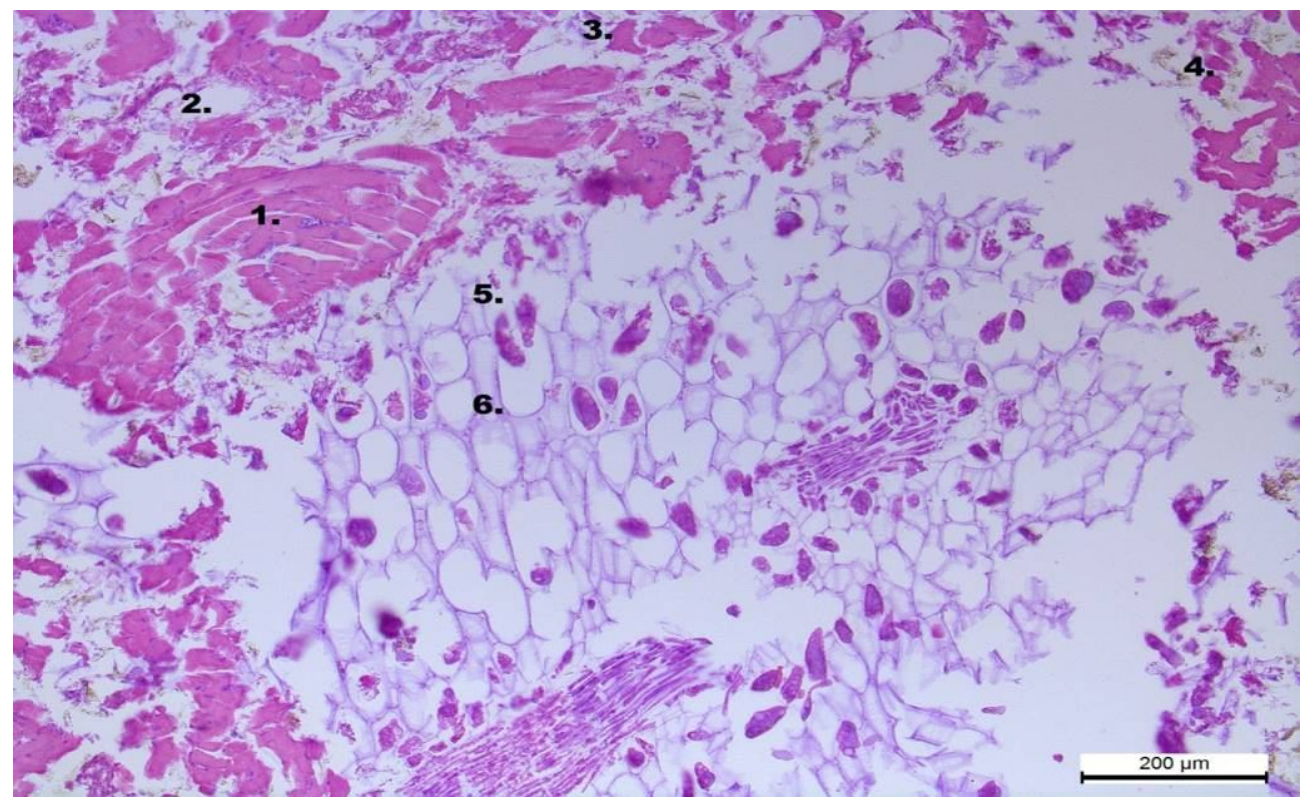

Figure 7. Sample 4 «15\%», A - hematoxylin and eosin. Eyepiece 10. Lens 10.

(1 - muscle fibers; 2 - fat tissue; 3 -onion; 4 - bread; 5 - lupine flour; 6 - Elecampane)

In Figure 8 at PAS reaction with eyepiece 10 and lens 10 and 10 it was identified plant part (1) and meat part (2) . In accordance with our compounding plant share increased by $15 \%$, which significantly increases its content in minced meat, that adversely affects the taste.

In Figure 9 it is depicted the vacuoles of lupine flour with hematoxylin and eosin (A) with eyepiece 10 and lens 30 and PAS reaction (B) with eyepiece 10 and lens 20, which have the appearance of spherical polygonal vacuoles and nuclei in the center of the cell well absorbing moisture. 


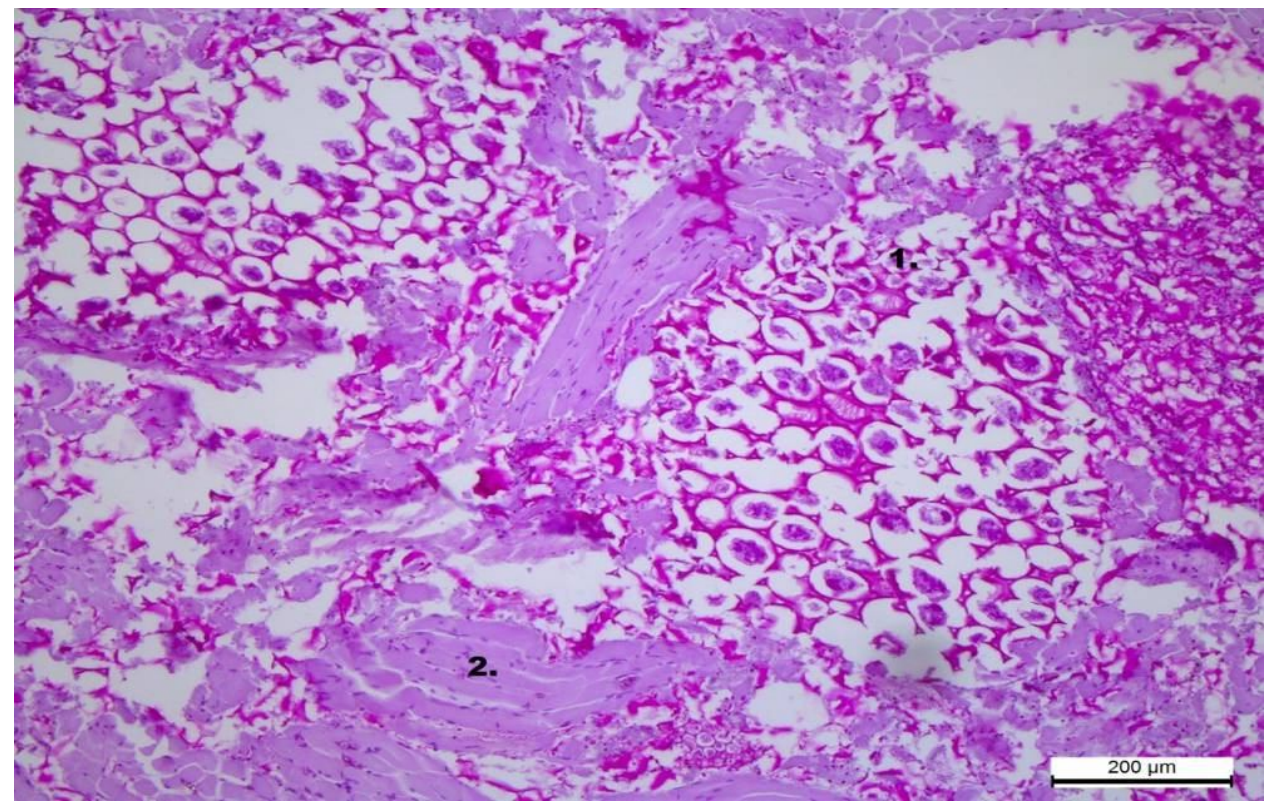

Figure 8. Sample 4 «15\%», B - PAS reaction. Eyepiece 10; Lens 10. (1 - vegetable part, 2 - meat part)
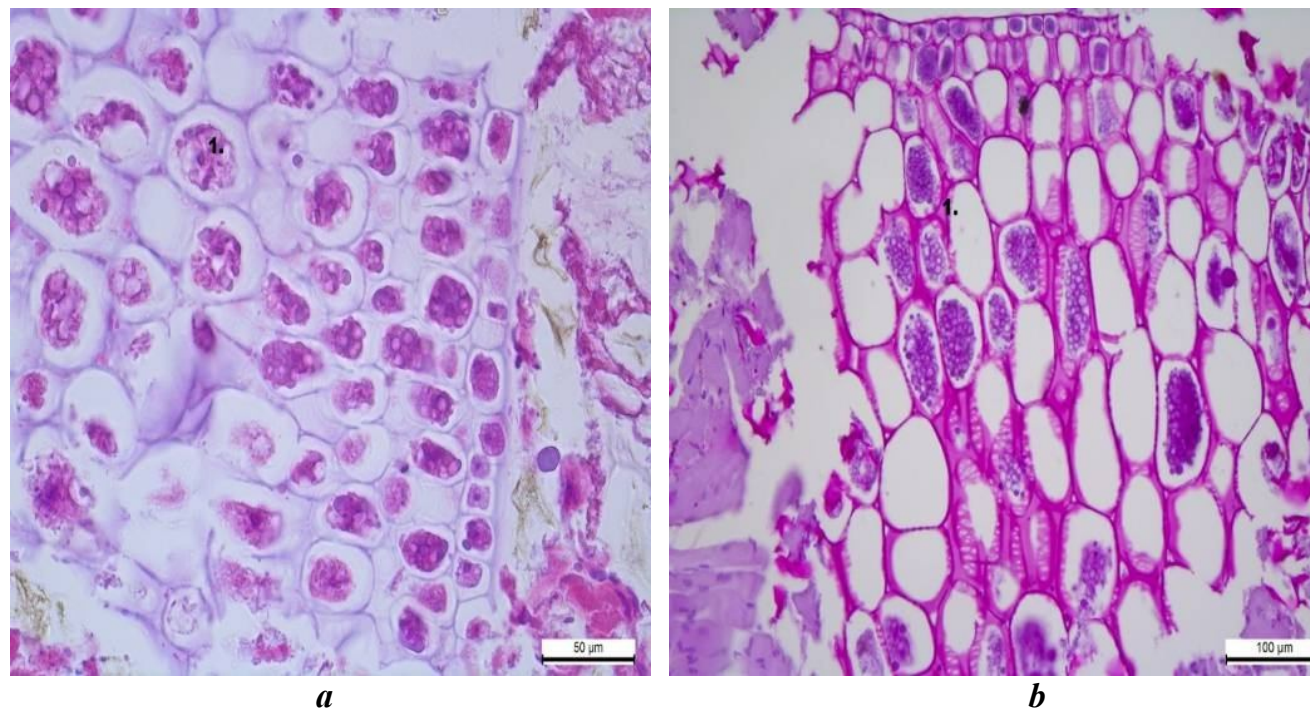

Figure 9. Lupine flour

a: A - hematoxylin and eosin. Eyepiece 10; Lens 30. b: B - PAS reaction. Eyepiec 10; Lens 20.

In Figure 10 it is presented a Elecampane root powder as part of its content in ground meat small portion, by hematoxylin and eosin (A) and PAS reaction (B) with eyepiece. 10 lens. 20. Fibers are clear elongated shape, crowded, loose. 

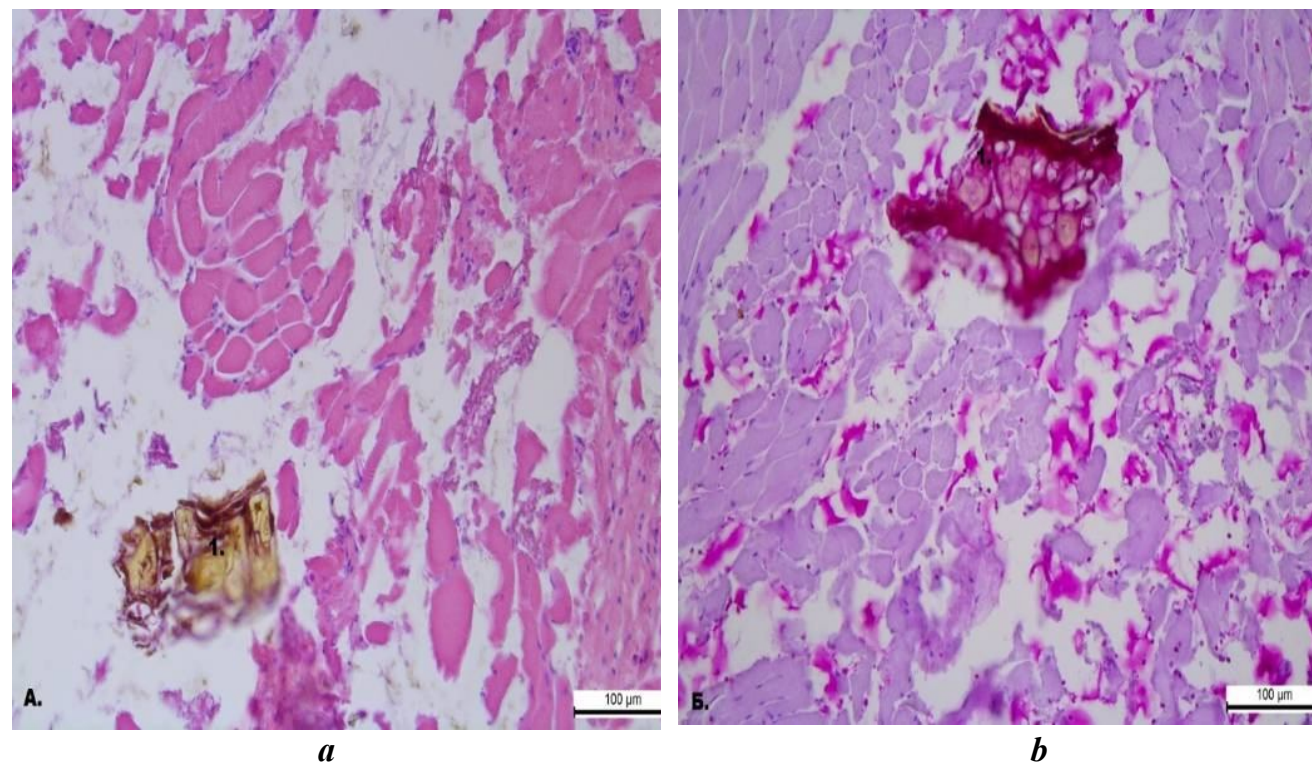

Figure 10. Elecampane root powder.

$a$ : A - hematoxylin and eosin. Eyepiece 10; Lens 20.

b: B - PAS reaction. Eyepiece 10; Lens 20.
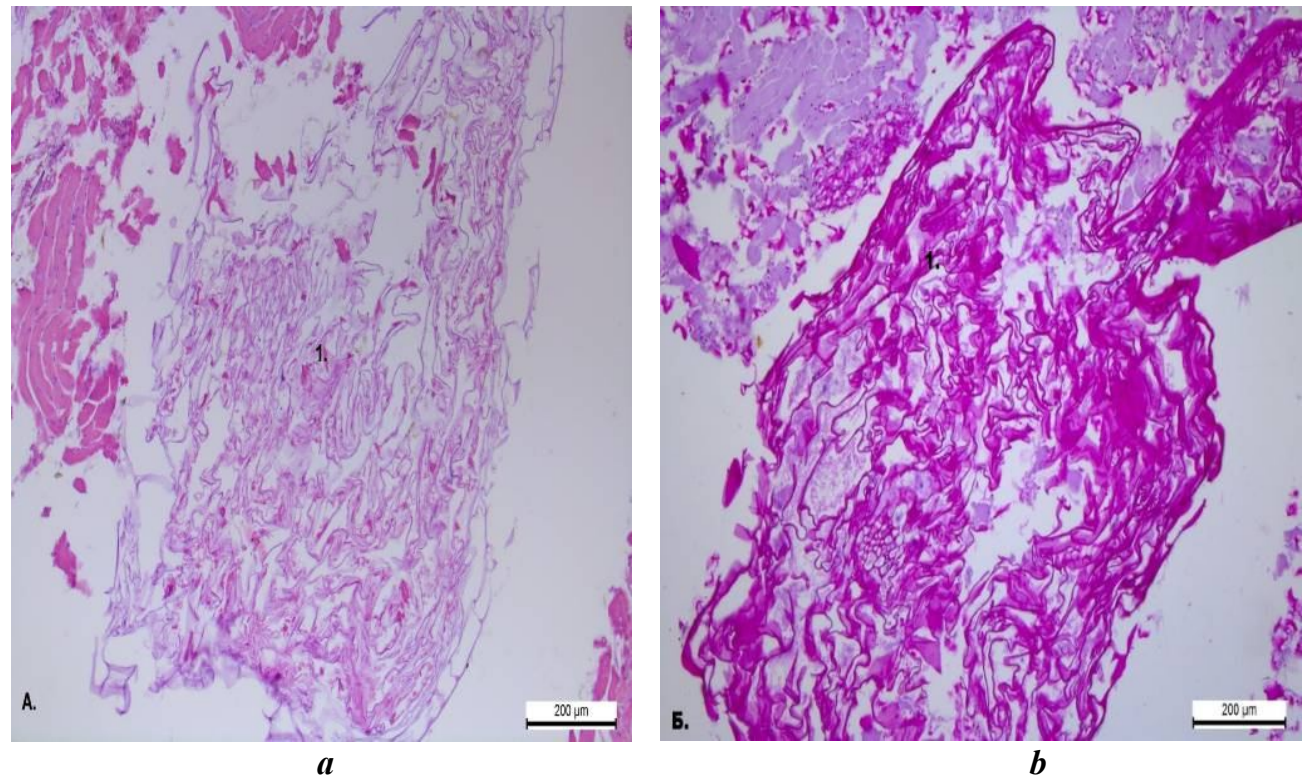

Figure 11. Chopped onion

a: A - hematoxylin and eosin. Eyepiece 10; Lens 10.

b: B - PAS reaction. Eyepiece. 10; Lens 10. 
In Figure 11 it is represented a onion by hematoxylin and eosin (A) and PAS reaction (B) with eyepiece 10 lens 10, fibrous structure, the fibers were loose since it was crushed in a meat grinder and minced had been mixed and it acquired the form of juice with soft.

\section{Conclusion}

Histological studies showed for the PAS reaction developed content in meat semis, meat and plant parts. For hematoxylin and eosin it was determined the composition of ground meat. Research has shown that after using 5\% of lupine flour - stuffing evenly homogeneous; $10 \%$ - allowed small bundles stuffing; $15 \%$ - causing uneven placement of muscle and plant parts, stuffing down, heterogeneous, crumbly. Research of microstructure simulated ground meat recipes shows that the introduction of more than $15 \%$ of lupine flour with semi causes loose structure products.

\section{References}

1. Paska M.Z, Masliichuk O.B. (2016), Mikrobiologhichna ta spozhyvcha kharakterystyka m'jasnykh posichenykh napivfabrykativ $\mathrm{z}$ dodavannjam ljupynovogho boroshna ta dyvosylu, Naukovyj visnyk LNUVM ta BT im. S.Z. Ghzhycjkogho, 18(4), pp. 121-123.

2. Paska M.Z, Masliichuk O.B. (2015), Ljupynove boroshno - vysokobilkovyj zbaghachuvach kharchovykh produktiv, Prodovoljcha industrija APK, 6, pp. 37-40.

3. Feldheim W. (2000), The use of lupins in human nutrition, Lupin, an ancient crop for the new Millenium Proceedings of the 9-th International Lupin Conference. Auburn University, pp. 434-437.

4. Golovchenko O.V., Saiko V.F., Fartushnjak A.T., Pruidze G.V. (2000), Sweet white lupin seeds as a source of pectin and protein for human nutrition, Lupin, an ancient crop for the new Millenium Proceedings of the 9-th International Lupin Conference. Auburn University, pp.451-452.

5. Horn D. (1987), Zum Nachweis pflanzhcher Eiweisszubereitungen in Fleischerzeugmssen mil histilogischen Untersuchunssverfahren Fleisch-wirtsch.

6. Journal, (2006-2008), Nutrition and Society Magazine, Economy, Moscow.

7. Gerhard F., (2006), Meat Products Handbook: Practical Science and Technology, Woodhead Publishing.

8. Shurduk I., Serik M., Antonenko S., Fedak N. (2014), Effect of protein and mineral additive on consumer characteristics of meat emulsion products, Ukrainian Food Journal, 3(4), pp. 524-534.

9. Golovko M., Serik M, Golovko T., Polupan V. (2014), Microstructural characteristics of minced meat products from use of protein-mineral additive, Ukrainian Food Journal, 3(2), pp. 243.

10. Farouk M.M., Frost D.A., Krsinic G., Wu G. (2013), Phase behaviour, rheology and microstructure of mixture of meat proteins and kappa and iota carrageenans, Food Hydrocolloids, 25(6), pp. 1627-1636.

11. Zhao L., Cai X., Huang Sh., Wang Sh., Huang Y., Hong J., Rao P. (2015), Isolation and identification of a whey protein-sourced calcium-binding tripeptide Tyr-Asp-Thr, International Dairy Journal, 40, pp. 16-23.

12. Belloque J. (2002), Analysis of soyabean proteins in meat products, Food Sc. Nutrit., 42(5), pp. 507-532. 
13. Bookwalter G. N. (1978), Soy protein utilization in food systems, Adv. Exp. Med. Biol., 105, pp. 749-766.

14. Flores-Mungula M. E. (2000), Detection of adulteration in processed traditional meat products, J. Muscle Foods, 11, pp. 319-325.

15. Giovannacci I. (2004), Species identification of meat products by ELISA, International Journal of Food Science \& Technology, 39(8), pp. 863-867.

16. Haeney M. R. (1982), Soya protein antibodies in man: their occurrence and possible relevance in coeliac disease, J. Clin Pathol., 35, pp. 319-322. 